\title{
Mapping Art History in the Digital Era
}

Jorge Sebastián Lozano

This is an Author's Original Manuscript of an article published in The Art Bulletin

Volume 103, 2021 - Issue 3, pages 6-16, published online: 31 Aug 2021 [@ copyright the College Art Association], available online at: https://www.tandfonline.com/doi/abs/10.1080/00043079.2021.1882819

Just as for the rest of the humanities, a roadmap for the discipline of art history in the past few decades would show a tangle of unexpected turns. Art history has undergone the linguistic turn, the material turn, the pictorial turn, the global turn, and, of course, the spatial turn, to name a few; what is more, there is the discipline's recent convergence with digital technologies. Already in 2004, while reviewing two recent contributions to the field, Larry Silver could assert in The Art Bulletin that "art is created as much in place as in time, making some self-aware form of artistic geography essential to the future of the discipline."1 Much more recently, Paul Jaskot hailed spatial analysis as "the most productive point of intersection [of art history] with digital methods.",2

Such claims attest to an important change in the discipline of art history, countering its longstanding lack of attention to the use of geographical tools. Our traditional hesitation to adopt such instruments is often supported by Ferdinand Braudel's famous assertion about the preference for museum catalogs over artistic atlases. ${ }^{3}$ Could Google Earth's satellite views, while jumping from one location on the globe to another, ever be put to a rigorous art historical use? Are digital maps really causing a turn in our practices? Or will they be just one more step in that long tradition of neglect, precisely at a time when this kind of electronic information is ubiquitous in ordinary life and for many other scientific disciplines? What follows is an attempt 
to raise these and some other useful questions; while not all of them will be answered, we can gain some leads from the available experiences.

\section{From Close to Distant Visualization and Back}

Traditionally, we art historians have been more interested in the specific and the extraordinary over the general and the average; put in geographical terms, in places rather than in spaces. However, a renewed attention is being paid to what happens within large-scale, even global contexts. My scope here encompasses the intersection between these broader frameworks and digital cartographic technologies, usually categorized as GIS (Geographic Information Systems). A number of methodologies based on digital tools already seem to enjoy a solid acceptance within the community of digital art history, such as network analysis, interactive 3D imaging of objects, buildings, or urban settings, and virtual, augmented, and extended reality. ${ }^{4}$ Nevertheless, the analysis of entire regions, periods, cultural traditions, or their global circulations is still quite exceptional within digital scholarship, as it always has been within "analog" art history.

On a theoretical level, methodologies in favor of this approach are already available, including most notably the dichotomy between close and distant reading posited by Franco Moretti and other literary historians. ${ }^{5}$ Like traditional literary critics, most art historians throughout the centuries have chosen to focus closely on individual, exceptional artworks. A different, "distant" viewing approach may focus on the average, even banal works that constitute most of the artistic production in any era. This would bring to light a less stellar, but probably more faithful view of the past of any given society. In the end, it is a matter of being able to choose between depth or breadth in presenting the history of art — of going back and forth in the scale of analysis, depending on the goals and the circumstances. Moreover, the ability to test analyses and share results instantaneously and interactively, as opposed to the painstaking 
process of preparing an "analog” printed map, makes these approaches worthy of additional efforts.

This methodology can claim illustrious ancestors within the discipline. A serial approach was adopted and theorized by champions of art historical formalism like Alois Riegl (18581905), Henri Focillon (1881-1943), and George Kubler (1912-1996). Series and sequences became the key categories for that kind of analysis, the units that shaped them being only witnesses to larger historical forces at play. The longue durée, total-history project of Fernand Braudel (1902-1985) provides another precedent for this horizontal, inclusive view of history. Nevertheless, any attempt to incorporate world dimensions into art historical scholarship has had obvious practical limitations, as a macroanalysis of evidence in such massive amounts is surely beyond the abilities of most individual researchers. This is where computing may be able to provide previously unfeasible resources for the meaningful integration and useful visualization of data in their thousands or even millions. Could we now map the world's art as a discovery resource for holistic interpretation, going beyond merely descriptive or topographical accounts?

A necessary step in that direction is the widespread adoption of structured data models. Any integration of information from different sources will rely on its semantization, allowing independent systems to share not just their data, but also their internal hierarchies, as well as implicit or explicit relationships. Let me give just two geographical examples. A field entitled "Origin" or "Location" in any given museum database is unintelligible in itself, if it is not further qualified as the object's place of production, the alleged location or "school" of its author, any step in its trade or provenance history, or the original setting of that collection. Museums and historical collections (within the broader heritage community, usually referred to as GLAMgalleries, libraries, archives, and museums) already have an excellent groundwork for this purpose, thanks to CIDOC's Conceptual Reference Model. ${ }^{6}$ On a different level, a city like 
Istanbul can be recognized under more than ten different historical or modern names. A human reader may be able to recognize most of them as referring to the same geographical entity, but a digital system will not, unless it is linked to a controlled vocabulary such as Pleiades or the Getty’s Thesaurus of Geographical Names (TGN). ${ }^{7}$

Since no institution can expect to register detailed, homogeneous historical data on a global scale, structured data is indispensable for the interoperability among different repositories of information, among different bodies of knowledge, including those that record some kind of geographical information. Thus, end users may be able to zoom in and out from the complexity of our data, as long as that complexity has been transferred into the integrated repositories or search interfaces. In other words, shared and linked data could offer inspiring insights on a global scale and abundant specific instances_-both multum and multa. Ideally, maps that visualize large bodies of art historical information may help us to discover previously overlooked objects or agents, and thus to consider additional contexts and connections beyond the usual narratives. On the other hand, maps were always a stimulus for exploration, even if only within our minds. We should not underestimate the serendipitous associations that innovative visualizations can trigger.

\section{Great Implications?}

Moving from desiderata to actual realizations, it is essential to identify which questions in art history can benefit from GIS, since not all will. We humans can focus on the tasks where we excel (inference, interpretation, judgement, criticism, causal explanation), while being supported by digital tools when the size or count of data exceeds our abilities, which often happen to be the sorts of assignments where computers are very apt: for instance, spotting patterns but also outliers or statistical anomalies. 
A fine example is the work carried out by Béatrice Joyeux-Prunel and the Artl@s research group under her direction. ${ }^{8}$ Among other things, it has provided a model resource for historians of modern and contemporary art who want to extract the rich information provided by so many exhibition and sales catalogs from the nineteenth and twentieth centuries. Their databases successfully integrate geographical data from these traditional sources, fostering a decentering of the usual historiographical narratives about modern art. As a result, the prime position of Paris for the birth and development of the avant-gardes is not denied, but it is redressed by a more balanced and fully documented account of the professional networks woven in other cities by artists, critics, dealers, and collectors.

Their work has also led to a focus on artistic circulations, providing insightful theorization about the possibilities for a global history of art. ${ }^{9}$ Aside from questioning center-periphery dichotomies by carrying out quantitative studies of specific trajectories, it involves issues such as the creation of narratives based on precise spatial data, the synoptical visualization of scattered or serial information, the geographical distributions that textual sources or formalist approaches do not usually hint at, the spatiotemporal relationships that dynamic maps render more easily identifiable, and the networks of competition and reward at work behind artistic production. Joyeux-Prunel has insisted on the object-based character of this approach, one that avoids both the essentialist, nationalist accounts of old Kunstgeographie (art geography) and a postmodern relativism where discursivity replaces material conditions and accurate information. ${ }^{10}$ Digital media can finally provide easy access to advanced geographical tools for scholars from many disciplines. The fact that such tools are instantaneous and interactive, allowing for constantly changing questions and spatial frameworks, renders them all the more helpful.

The changing relationships between natural and cultural borders, and the historical evolution of the latter, is a staple feature of GIS projects. The geographical visualizations 
incorporated into an ambitious database of Latin American colonial painting invite us to interrogate the evolving viceregal demarcations, as well as the establishment of alternative centers and crossroads for influences from various origins. ${ }^{11}$ Consequently, users move toward a broad range of issues (the dissemination of objects, the routes and modes of trade, homogeneity or heterogeneity in the productions from a single center, and so forth) and processes (influence from colonial metropolises or other ruling cultures, imitation, hybridization, acculturation, the role of nomadic communities, and more).

Obviously, mobile objects and built environments require separate approaches. Careful attention must be paid to the differences between places, areas, and routes; locations, names, and connections require different categorizations. In all cases, however, the increase in georeferenced information and the use of handheld devices prompt questions based on objects or places that the user is experiencing at that very moment: Where did the materials for this building come from? What other artisanal productions originate from the same period and center as this rug? Where can similar examples of this glazed ceramic technique be found today? What route did this decorative motif follow while being copied and transformed? Where else was this painting on view in the past? ${ }^{12}$ Providing immediate, on-the-spot answers to these kinds of questions requires technical tools that are currently accessible or are easy to deploy. Georeferenced, refined, and structured datasets are not so readily available, but the situation is slowly improving.

Maps invite us to pin multiple narratives on top of a common cartographic framework. For instance, the artists database of the RKD (Netherlands Institute for Art History) offers a simple but effective visualization of the life-and-work trajectory of many Dutch artists. ${ }^{13}$ Of course, the usefulness and accuracy can vary, depending on the available sources, but as a first contact with their itinerant lives, such a map can be tremendously valuable. The underlying technology is easily available; the key for a successful implementation is its combination with the 
extensive records of the RKD. Going one step beyond, once a museum catalog or any art historical database includes georeferenced records, it is increasingly easy to provide tools that allow us to combine institutional data and other geographical information supplied by the user. This might be a way to raise new research questions, or simply to increase public interest in their holdings. The RKD maps provide another excellent example, easily letting users superimpose their own datasets on a map or tile-layered images of historic maps. ${ }^{14}$

While maps may intuitively seem to be about physical locations, human experience about spaces is loaded with emotional and intellectual overtones, as well as historically contingent associations between places, agents, or events. Accordingly, one location can be viewed as an extension, in its physical aspects, dealt with by cartography; or as an intension, the human qualities of a space, its identifying elements; or as a relation to other places, within networks, routes, or territorial borders. ${ }^{15}$ For instance, the availability of materials has usually depended on the existence of natural routes for their displacement. However, as means of transportation improve, distances become less important, while other social elements such as political, cultural, or trade barriers change in importance through time.

Once fairly accurate representations of space are available, we usually move from topography toward topology. Connections, networks, and reticulations among different sites become the topics of interest, rather than their distances or their disposition on a map. The geography implicit in any textual source, the places mentioned therein, is usually indicative of relationships such as provenance, patronage, and setting, but also of the symbolic or imaginary realms. Visualizing those experiential relationships becomes the task for GIS and so-called deep maps, combining material and immaterial aspects of space, when topographically correct representations are already at hand. 
The universal experience of travel involves not just the spaces traversed but also, and very importantly, the time required to do so. Mapping tools such as those included in ORBIS incorporate these considerations by providing the users with land roads or ports of call, but also by letting them know the time cost and financial expense involved in traveling through, say, the Roman empire circa 200 CE. ${ }^{16}$ Another approach is employed in a spatiotemporal mapping of Ibn Jubayr's pilgrimage from Granada to Mecca in the twelfth century. It departs from the usual bidimensional representations of trips by adding a vertical axis that provides the temporal information. Moreover, a simple color code associated with the different moments of the journey signals the state of mood of the traveler, as reported by himself in his travelogue. ${ }^{17}$ These are just two examples of how, in the words of Johanna Drucker, "space, like time, is always relational, always produced as a factor of experiential or subjective effect."18 Thus, we need to explore geographic visualizations that show how experience makes space, expressing its affective, cultural, and relational aspects.

\section{Facts and Other Misrepresentations}

Traveling these digital roads requires a fair dose of precaution, too. Before joining the "rush to visualization," we ought to remember some tenets about data science. ${ }^{19}$ First and foremost, that data are never mere facts, as we usually presume them to be. Interpretation is built into every single piece of data in our records, no matter how seemingly objective they are purported to be. This is true for empirical sciences, and all the much more for the humanities. For this reason, Drucker has repeatedly argued in favor of "capta," instead of "data", as a better way to name the information that lies within our repositories. ${ }^{20}$ Our records are not merely given to us; they have 
been captured and registered through a system of practices, techniques, institutions, professions, objects, and their digital surrogates.

Therefore, the inherent interpretive nature of our graphical expressions should be frankly acknowledged, making it work to our advantage — for instance, by never hiding the conventions, assumptions, and standards at work within those digital graphical expressions. Map legends have fulfilled this task for centuries, and where digital information is concerned, additional metadata must be properly identified and credited. A not-so-distant scenario where this will prove essential is the automated annotation of incomplete records by means of artificial intelligence. A distinction between data based only on algorithmic comparisons and those curated by human experts must be made clear to all users.

Maps are particularly revealing when it comes to fragmentary information. Gaps in the historical register can be more easily glossed over in a narrative discourse than in a geographical or chronological visualization that renders them instantly visible. Silences have something to tell us: at the least, about the power structures that shape historical information; at the most, about indifference to future memory. In other cases, absence is simply a consequence of change, as with old streets that have disappeared from a city plan. Acknowledging these voids and complexities, making them visible to the users, is the only way forward. Sometimes the opposite is true: one can delve endlessly into dense spots, where local values, identity projections, and emotional experiences accumulate, attracting close attention from researchers. Digital tools make it particularly easy to show or hide layers of information, which is sometimes truly overwhelming in its richness. The existence of two long-running projects focused on the digital representation of Venice and its urban history is more than a telling coincidence in this regard. ${ }^{21}$ Likewise, on a different scale, the rise, expansion, and interconnectedness of Gothic architecture in medieval 
France can be much more aptly visualized through an interactive visualization than on any printed map. $^{22}$

At the same time, important challenges are raised by the usage of precise terminologymore exactly, by the lack thereof. Grouping terms into conceptual typologies is necessary for any interpretive effort; otherwise, we are left with staggering amounts of individual instances which we simply cannot interpret. Digital information is even more based on the availability of stable and hierarchical labels in order to group and count instances that share any given feature. Quantitative maps, like most tools in the data-driven humanities, require stable and discrete identifiers. On the other hand, when we delve deep into data, many nonstandard instances appear that do not fit squarely within the labels, mixing or qualifying them instead.

Toponyms are a classic example of this kind of problem, and not just because of multilingual and chronological diversity; as mentioned before, controlled vocabularies and gazetteers increasingly allow us to handle such variations properly. Sometimes, the geographical concepts themselves are so loaded with biased interpretations that accepting a straightforward equivalence between sources and modern usage can be disastrous. ${ }^{23}$ Locations mentioned in a text can be automatically encoded and transferred to a map, visualizing the geographical settings or itineraries implicit in any given narrative. However, any such translation of narrative to maps does some violence to the original, textual form of that information. Differently than what happens with maps, space in narrative accounts is neither Cartesian nor continuous, but subjective and irregular. Finally, locations mentioned within a catalog or database are not generic: in order to allow meaningful queries and analysis, they have to be qualified as places of production, origin, acquisition, usage, or destination; or linked to biographical references to the maker, trader, or user; and so on. In other words, it is essential to specify what kind of 
relationship is associated with the reference to a location; otherwise, it becomes useless or even misleading.

Similar considerations apply to cultural otherness. Historical maps of cities or regions provide invaluable information and can be easily viewed and superimposed on current digital mapping tools. This can be used to great advantage, signaling not just the factual changes between past and present, but also the ways in which previous notions about space or places differed from current ones. ${ }^{24}$ However, they are often very idiosyncratic, as a result of ideological, stylistic, or technical constraints. Careful consideration of these specificities is required, lest we make them into spectacular but anachronistic projections. Such opportunities and dangers have led most theorists to emphasize the usefulness of historical GIS maps as tools and processes rather than outputs. Digital tools enhance the interactive aspect of this spatial hermeneutics, in the tradition of many other atlases, the Mnemosyne Atlas of Aby Warburg (1866-1929) being just one prominent example, even if it completely lacks a geographical approach. Any visual atlas is a field for disciplinary exploration, putting images to work, having them lead interpretation and not just illustrate it. Testing hypotheses, discovering patterns, assembling evidence for arguments, detecting changes and networks-digital cartography applied to art historical enquiry could probably better live up to its promise as an aid for research and study than as a set of beautiful, groundbreaking visualizations. Gathering and modeling digital data about any object from the past is not merely a matter of expertise in computing tools. It involves asking questions about value, meaning, influence, and other elements that return us to the core of the discipline. Turning those questions into data modeling that allows us to transform evidence into reliable answers should be an important skill for current and future art historians.

Overcoming the false neutrality and objectivity of geographical information, and understanding its constructed character, should lead us toward models of visualization that embed 
interpretation, that beg the question about the position of the past or present spectator, and that make such a position self-evident. As Drucker articulates it, "Information spaces drawn from a point of view, rather than as if they were observer-independent, reinsert the subjective standpoint of their creation into the graphical expression." ${ }^{25}$ Maps that compare with network diagrams, that emphasize comparative, relational information, should be useful tools for the same goals.

Any discussion about global-scale visualizations of art historical objects instantly becomes part of the larger debate between the alleged universalism of art and the cultural specificity of each object. It is well beyond the scope of my study to resolve that discussion, but merely asking the questions implies an opinion about it. The same happens for any attempt to provide global information about art: as stated by the editor of one of the few world art atlases, this kind of book "allows exceptional insights both into what unites all art and into what makes it so varied." 26 The still-predominant narrative, even if subject to constant criticism and growing overhaul, follows the "pyramids to Picasso" geographical and conceptual route. ${ }^{27}$ It meanders from Egypt and the Middle East to Greece, Italy, and the Mediterranean, then expands to Western Europe, and jumps to the Americas. A text or a list can strive to hide from sight how that narrative leaves out vast regions of the globe for most of human history. On a world map, such selective storytelling instantly reveals its discretionary and biased character.

International organizations have managed to offer a slightly more egalitarian approach, if only in recent times. Each year, UNESCO publishes the World Heritage Map, which shows both a world map and an additional insert for Europe and the Mediterranean, where the density of cultural properties listed as World Heritage sites is much higher than in other regions. ${ }^{28}$ The project is supported by National Geographic, which in turn provides ample coverage for the listed sites on its many publishing channels. ${ }^{29}$ While UNESCO's map is quite restrained and descriptive, National Geographic's apparent approach to World Heritage sites considers them 
mostly as spectacular destinations for travel, without any attempt to take advantage of digital cartography. Yet another version of UNESCO'S list is available as an online, interactive world map, powered by GIS software from Esri, that offers a much more administrative and declarative approach, allowing filters, categorized searches, data exports, and so forth. ${ }^{30}$ It does not aim directly at research, and the associated catalog records are quite limited, but at least it offers a global framework and an initial domain for data harvesting and visualization. These resources show how the same geographic information can serve strikingly different purposes.

A praiseworthy initiative in this direction is Harvard University's WorldMap, “an online, open source mapping platform developed to lower barriers for scholars who wish to explore, visualize, edit, and publish geospatial information." ${ }^{31}$ This platform deserves attention not just because the concept attempts to combine the best from both GIS software and online mapping platforms. Although now it belongs to Harvard's Center for Geographic Analysis and is used mostly by scholars from the social sciences, the concept was originally developed by the art historian Suzanne Blier. Even more, its first iteration was AfricaMap, which was soon expanded to a worldwide reach. ${ }^{32}$ In a way, this fascinating case shows how attention to one specific region can foster the creation of new geographic tools that propose broader sets of questions and interdisciplinary approaches. It also proves how most of us art historians continue to make very little use of these tools.

In analogous fashion, GIS might facilitate the development of alternative worldviews, shifting the predominant accounts about global art networks. Peter Frankopan has obtained widespread attention (and some criticism) with his proposal of a new narrative for world history in which Asia plays the leading role from ancient times to the present. ${ }^{33}$ What kinds of geographical visualizations would be needed to foster the creation of the corresponding world maps? Once we understand that every map has an implicit narrative woven within it, how could 
we make sure that those narratives are not simply imposed on unaware viewers, but made explicit and thus more subject to evaluation and critical scrutiny? Will the mere accumulation of information and facts cause new configurations to suggest themselves to map users by the sheer magic of visualization tools? As scholars, what can we learn from previous attempts to combine art history and geography, ones that all too often were tainted by racist, nationalist, or Eurocentric ideologies ${ }^{34}$ Global approaches to digital art history provide healthy antidotes to those essentialist accounts, rendering circulations and contacts more easily visible. But they require a better understanding of their complexity, overcoming bipolar schemes of center and periphery, and tracking horizontal, multidirectional, or networked relationships instead.

\section{Teams and Tools (in That Order)}

Methodological implications remain theoretical until pragmatic issues and human resources are taken into consideration. The requirements of GIS work for research on art history do not differ much from other areas in the digital humanities. ${ }^{35}$ First, the potential scientific interest must be convincing enough to begin committing efforts and resources to this kind of analysis, still rare within the discipline. It is also vital to ensure some degree of professional recognition for results (e.g., websites, software, datasets, or databases) that often do not fit traditional channels (e.g., journal articles, monographs, or exhibition catalogs). Interdisciplinary work usually involves teamwork, and proper credit is due to all staff involved, including data encoders, engineers, and technology experts, not simply for ethical reasons, since they are the workforce that makes these processes possible, but also because they often play a much more than instrumental role. For comparable reasons, GIS projects represent long-term efforts, in which a clear schedule and a sustainable commitment should be put in place from the beginning. Crowdsourcing is only one of 
the paths to follow, just as research is but one of the communities revolving around art historical knowledge.

In fact, information made available online has usually attracted unexpected users, beyond those originally targeted, who put the platforms to use in contexts never planned by the developers. This means not only that art historical resources could and should attract the attention of other communities but also that art historians would do well to keep abreast of what is going on within the broader GIS and data visualization fields. Similarly, a geographical approach easily brings other experts into the conversation, from archaeologists and anthropologists to cultural or regional historians. ${ }^{36}$ Art history has been repeatedly renewed and enriched by interdisciplinary or multidisciplinary approaches, some of which could now lie in the areas outlined above. Indifference or distrust toward quantitative methods can be overcome by easily available training, good methodological models, and areas of shared interest. "Translators," that is, professionals with a dual set of skills, or who are at least minimally conversant with an additional field beyond their main body of disciplinary knowledge, are often the spark for a successful collaborative effort.

GIS tools are in continuous growth and development. ArcGIS from Esri is probably the most used commercial package, not just on the properly cartographical side, but also for its visualization and storytelling abilities. ${ }^{37}$ Its main contender from the open-source community is QGIS, differences between them being quite context-specific. ${ }^{38}$ In fact, other tools are freely available for digital humanities practitioners pursuing geographical approaches and visualizations. Arches, a Cultural Heritage Inventory and Management platform, or Neatline, a plug-in for the Omeka collections publishing platform, provide ample space for a whole range of varying needs and resources among the heritage and art historical community. ${ }^{39}$ 
In the end, the availability of appropriate technologies is key, of course, but our mindsets may matter just as much. For institutions and for individuals, claiming and practicing an openaccess approach to culture and scholarship will be the most transformative element in fostering an environment that invites innovation. Openly shared software, datasets, standards, training —all these are fitting counterparts for GIS analysis, which is inherently open-ended, always incomplete, always subject to the addition of more data, new tools, and unanticipated perspectives. Our methods, both inherited and more recent ones, provide a solid ground for another reassessment of what we do as art historians. As so aptly expressed by Jaskot, "We can begin to map digitally our existing art histories in order to learn more about the nature of arthistorical work. ${ }^{, 40}$ Self-knowledge may come to be the best reason to pursue this experiment.

\section{Bio}

Jorge Sebastián Lozano is an assistant professor at Universitat de València. He was a research fellow at the Real Colegio Complutense at Harvard University. A collaborator in Sofonisba Anguissola's exhibition at Museo del Prado (2020), he is also involved in SILKNOW, an EUfunded project on silk in early modern times [Department of Art History, Universitat de València, Avda. Blasco Ibáñez 28, 46010 Valencia, Spain, jorge.sebastian@uv.es].

\section{Notes}

The author wishes to express his gratitude to the journal editors for their kind invitation to contribute to this section. This research is partly supported by the SILKNOW research project, which has received funding from the European Union's Horizon 2020 research and innovation 
programme under Grant Agreement Number 769504. All URLs in the article are valid as of November 7, 2020.

${ }^{1}$ Larry Silver, review of Atlas of World Art, ed. John Onians, and Toward a Geography of Art, by Thomas DaCosta Kaufmann, Art Bulletin 86, no. 4 (December 2004): 786.

${ }^{2}$ Paul Jaskot, "Digital Methods and the Historiography of Art," in The Routledge Companion to Digital Humanities and Art History, ed. Kathryn Brown (New York: Routledge, 2020).

3 "Nous avons des catalogues de musées, non pas des atlas artistiques." Fernand Braudel, La Méditerranée et le monde méditerranéen à l'époque de Philippe IIe (Paris: Armand Colin, 1949), 613.

${ }^{4}$ Publications and forums on digital art history are steadily increasing: see, for instance, the International Journal for Digital Art History, https://dahj.org/; or the most recent survey (cited above) edited by Kathryn Brown, The Routledge Companion. For an excellent, forward-looking evaluation of the field, see Nuria Rodríguez-Ortega, "Digital Art History: The Questions that Need to Be Asked," Visual Resources, 35, no. 1-2 (2019): 6-20, https://doi.org/10.1080/01973762.2019.1553832.

${ }^{5}$ Franco Moretti, Atlas of the European Novel (London: Verso, 1998). For an account of the terminology and its forerunners, see Ted Underwood, “A Genealogy of Distant Reading,” Digital Humanities Quarterly 11, no. 2 (2017), http://digitalhumanities.org/dhq/vol/11/2/000317/000317.html.

${ }^{6}$ See "What Is the CIDOC DRM?" http://www.cidoc-crm.org/. CIDOC is the International Council for Documentation, a committee of ICOM, the International Council of Museums. 
${ }^{7}$ See B. Siewert-Mayer, W. Röllig, H. Kopp, Sean Gillies, Francis Deblauwe, and Eric Kansa, “Instanbul, a Pleiades Place Resource,” 2013, https://pleiades.stoa.org/places/77402394; and Getty Thesaurus of Geographic Names Online, “Istanbul,” 2016, http://vocab.getty.edu/page/tgn/7002473.

8 “Artl@s,” https://artlas.huma-num.fr/en/. See also Béatrice Joyeux-Prunel, “Digital Humanities for a Spatial, Global, and Social History of Art," in The Routledge Companion.

${ }^{9}$ Thomas DaCosta Kaufmann, Béatrice Joyeux-Prunel, and Catherine Dossin, "Reintroducing Circulations: Historiography and the Project of Global Art History," in Circulations in the Global History of Art, ed. Kaufmann, Joyeux-Prunel, and Dossin (New York: Routledge, 2015), 1-22. ${ }^{10}$ Ibid., 16.

11 "Proyecto ARCA—Cultura visual de las Américas," http://artecolonialamericano.az.uniandes.edu.co:8080/. See also the counterpart online publication, Jaime H. Borja Gómez, Los ingenios del pincel: Geografía de la pintura y cultura visual en América colonial (Bogota: Universidad de los Andes, 2019), https://losingeniosdelpincel.uniandes.edu.co/.

${ }^{12}$ For this last specific question, resources such as "Mapping Paintings," http://www.mappingpaintings.org/, developed by Jodi Cranston, are bound to provide interesting insights about provenance and reception history as their coverage increases. See also Cranston, "Mapping Paintings, or How to Breathe Life into Provenance," in The Routledge Companion.

${ }^{13}$ See the RKD website for entries such as "Antonio Moro," https://rkd.nl/en/explore/artists/57803; or "Jan van Scorel," https://rkd.nl/en/explore/artists/71591.

14 “RKD Explore," https://rkd.nl/en/collections/services-tools/rkd-maps\#/ (requires registration). 
${ }^{15}$ See Franco Moretti, Graphs, Maps, Trees: Abstract Models for Literary History (London: Verso, 2007).

16 "ORBIS, The Stanford Geospatial Network Model of the Roman World," Stanford University, https://orbis.stanford.edu/.

${ }^{17}$ See “MIT AKDC LayerCake Demo," https://vimeo.com/329235502. This reconstruction of Ibn Jubayr's journey was built using the prototype of LayerCake, an interface for mapping narratives across time and space, that continues to be developed at MIT's Aga Khan Documentation Center: "LayerCake," https://layercake.mit.edu/.

${ }^{18}$ Johanna Drucker, Graphesis: Visual Forms of Knowledge Production (Cambridge, MA: Harvard University Press, 2014), 82.

${ }^{19}$ Ibid., 126.

${ }^{20}$ Ibid., 129. See also Johanna Drucker, "Humanities Approaches to Graphical Display," Digital Humanities Quarterly 5, no. 1 (2011).

21 "Venice Time Machine," https://www.epfl.ch/research/domains/venice-time-machine/, part of the Time Machine Project of the École polytechnique fédérale de Lausanne (EPFL); and "Visualizing Venice: Exploring the City’s Past," a collaboration of Duke University, Università IUAV di Venezia, and Università degli studi di Padova, http://www.visualizingvenice.org/.

${ }^{22}$ As in "Mapping Gothic France," a classic example of art historical GIS, developed at Columbia University, http://mappinggothic.org/.

${ }^{23}$ See Susan Gagliardi and Joanna Gardner-Huggett, "Spatial Art History in the Digital Realm," Historical Geography 45 (2017): 26-29.

${ }^{24}$ Historical maps from the extraordinary David Rumsey Map Collection are readily available as layers in some geographical tools from Google: https://www.davidrumsey.com/.

${ }^{25}$ Drucker, Graphesis, 132. 
${ }^{26}$ John Onians, ed., The Art Atlas (New York: Abbeville Press Publishers, 2008), 10.

${ }^{27}$ Robert Nelson, “The Map of Art History,” Art Bulletin 79, no. 1 (March 1997): 29-30.

28 “UNESCO World Heritage Map,” https://whc.unesco.org/en/wallmap/. Although dubbed on the site as a "wall map," it is available both in printed and in digital (PDF) versions.

29 “National Geographic World Heritage," https://www.nationalgeographic.com/travel/worldheritage/.

${ }^{30}$ UNESCO Interactive Map," https://whc.unesco.org/en/interactive-map/.

31 "World Map," Center for Geographic Analysis, Harvard Univeristy, https://worldmap.harvard.edu/.

${ }^{32}$ Suzanne Blier, "Interview with Suzanne Blier on WorldMap, Easy-to-Use GIS," interview by Jared Green, American Society of Landscape Architects, at "The Dirt: Uniting the Built and Natural Environments," June 20, 2013, https://dirt.asla.org/2013/06/20/interview-with-suzanneblier-on-open-source-gis/.

${ }^{33}$ Peter Frankopan, The Silk Roads: A New History of the World (London: Bloomsbury, 2015).

${ }^{34}$ Something clearly elucidated by Thomas DaCosta Kaufmann, Toward a Geography of Art (Chicago: University of Chicago Press, 2004), 44-58.

${ }^{35}$ See Catherine Dossin, Nicole Ningning Kong, and Béatrice Joyeux-Prunel, “Applying VGI to Collaborative Research in the Humanities: The Case of ARTL@S," Cartography and Geographic Information Science 44, no. 6 (2017): 522-23, https://doi.org/10.1080/15230406.2016.1216804.

${ }^{36}$ See Onians, Art Atlas, 10.

37 “ArcGIS StoryMaps,” https://storymaps.arcgis.com/ (requires registration). See also Sébastien Caquard and Stefanie Dimitrovas, "Story Maps \& Co.: The State of the Art of Online Narrative Cartography,” Mappemonde, no. 121 (2017), https://doi.org/10.4000/mappemonde.3386. 
38 "QGIS: A Free and Open Source Geographic Information System,"

https://www.qgis.org/en/site/.

39 “Arches," Getty Conservation Institute and World Monuments Fund, https://www.archesproject.org/; and "Neatline: Plot Your Course in Space and Time," https://neatline.org/.

${ }^{40}$ Paul Jaskot, "Commentary: Art-Historical Questions, Geographic Concepts, and Digital Methods," Historical Geography 45 (2017): 94. 